\title{
Physical Properties of Sandy Soil Affected by Soil Conditioner Under Wetting and Drying cycles
}

\author{
M.I. Choudhary ${ }^{1}$, A.M. Al-Omran and A.A. Shalaby
}

\author{
Soil Science Department, College of Agriculture, King Saud University, \\ P.O. Box 2460, Riyadh 11451, Kingdom of Saudi Arabia
}

\begin{abstract}
الخصائص الطبيعية للتربة الزملية المتأثرة بملطفات التربة تحت دورات البلل و الجفاف

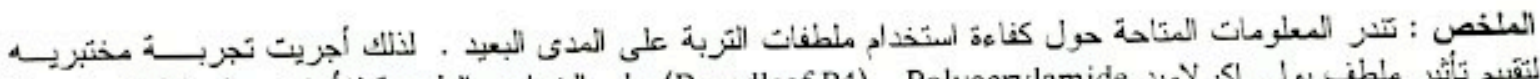

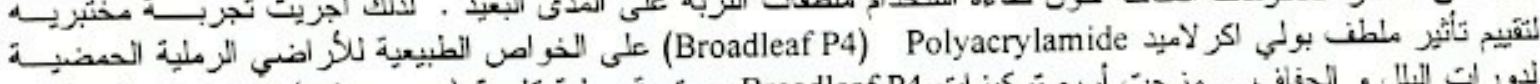

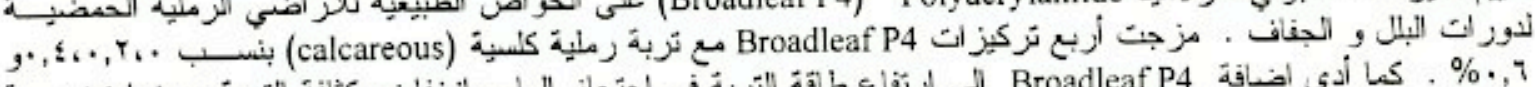

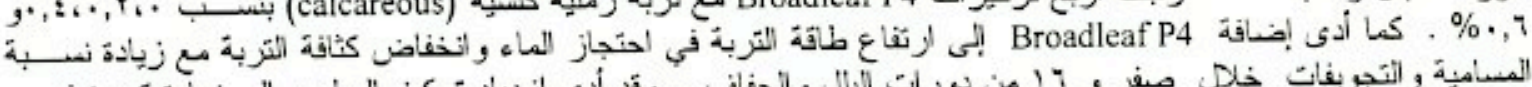

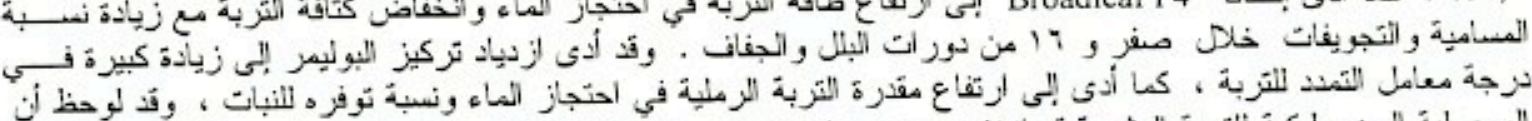

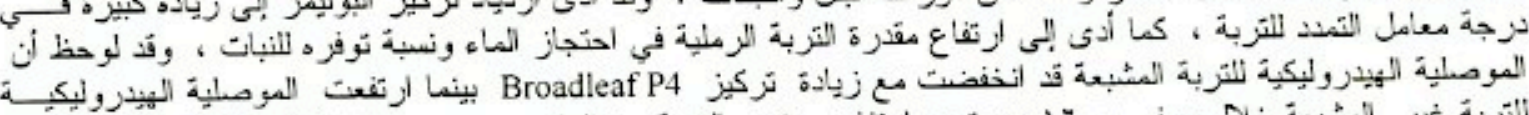

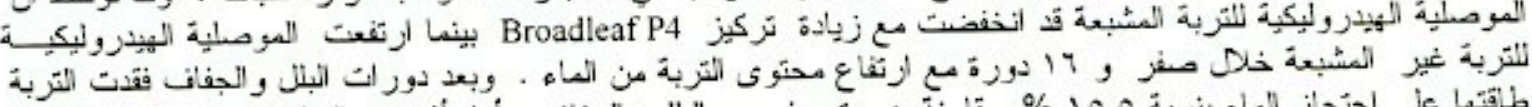

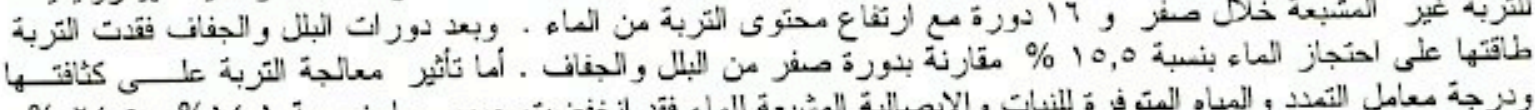

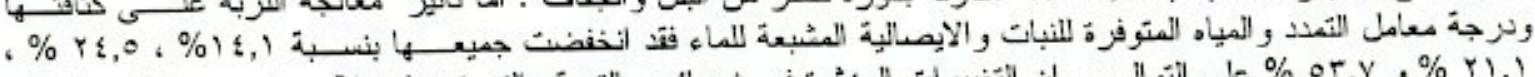

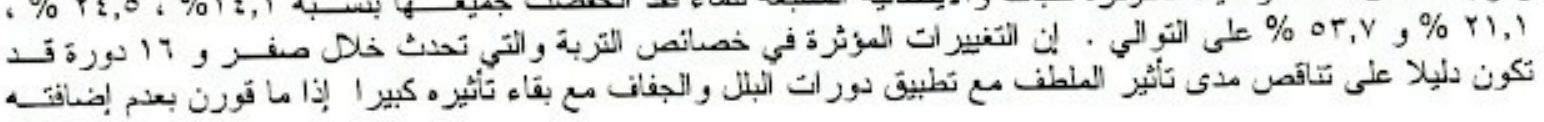

\begin{abstract}
Information on the effectiveness of soil conditioners over a prolonged period is scarce. A laboratory experiment was undertaken to evaluate the effectiveness of a polyacrylamide (Broadleaf P4) soil conditioner on the physical properties of sandy soil subjected to wetting and drying cycles. Four concentrations of Broadleaf P4 $0,0.2,0.4$ and $0.6 \%$ on dry weight basis were uniformly mixed with a calcareous sandy soil. Addition of Broadleaf P4 to sandy soil increased the water holding capacity, decreased the bulk density, and increased the porosity and void ratio at 0 and 16 wetting and drying cycles. The coefficient of linear extensibility increased considerably with increasing concentrations of the polymer. The addition of polymer at 0 and 16 cycles increased considerably the retention and availability of water in sandy soil. Saturated hydraulic conductivity decreased with increasing concentrations of Broadleaf P4 whereas unsaturated hydraulic conductivity at 0 and 16 cycles showed an increase with increasing soil moisture contents. After 16 wetting and drying cycles, the capacity of the soil to hold water was lost on average by $15.8 \%$ when compared to the 0 wetting and drying cycle. The effectiveness of the soil conditioner on bulk density, coefficient of linear extensibility, available water and saturated hydraulic conductivity was reduced on average by $14.1,24.5,21.1$ and $53.7 \%$, respectively. The significant changes in soil properties between 0 and 16 cycles suggested that the effectiveness of the conditioner decreased with the application of wetting and drying cycles. However, its effect was still considerable when compared to untreated soil under laboratory conditions.
\end{abstract}

$\mathrm{S}_{\mathrm{p}}^{\mathrm{o}}$ oil conditioners have shown promise of improved physical conditions of sandy soils in arid and semiarid regions. Numerous studies have revealed their effectiveness to improving soil structure, increasing water holding capacity and water conservation, and reducing infiltration rate and accumulative evaporation (Choudhary et al., 1995; Al-Darby et al., 1992; AlOmran, 1987; De Boodt, 1975). However, their use on a large scale was limited because of the high cost and inconsistent results as to their effects on the chemical properties of soil (Falatah and Al-Omran, 1995; Falatah et al., 1996). Advances in the chemistry of synthetic polymers have made them more effective and cost efficient, thus there has been renewed attention on their use as soil conditioners (Wallace and Wallace, 1990). However, there is sparse information on an important

${ }^{1}$ Corresponding Author. 
feature of these substances, namely their persistence in soil. This characteristic is important in any cost-benefit assessment because polymers have been used not only to minimize drought losses at germination and seedling establishment, but as long term aids to water supply over several years.

There have been very few, if any, long term studies conducted to measure the breakdown rate of polymers over a period of time. Several manufacturers suggest that polymers will benefit significantly the retention of soil water during a period of five years. The efficacy of polyacrylamide (PAM) treatments depends upon the rate of application, depth of application, weathering of soil, tillage operation and many other factors (Seybold, 1994; Wallace et al., 1986). Fox and Bryan (1992) reported a lasting effect of PAM up to 6 weeks. Shainberg et al. (1990) suggested that the infiltration rate of PAM-treated soils remained effective through a 7-day period between simulated rainstorms. Azzam et al. (1983) reported that the estimated degradation of PAM in soil is $10 \%$ per year.

Levy et al. (1992) suggested that wetting and drying cycles may cause degradation of PAM, resulting in reduced efficiency. Wang and Gregg (1990) reported that a synthetic hydrogel maintained structural integrity upon hydration and is less damaged by fertilizers and salts than starch-based hydrogels. Fonteno and Bilderback (1993) observed that irrigation and drying cycles resulted in decreased substrate volume, water retention and bulk density, and increased non-capillary pore space when a synthetic polyacrylamide (Super Sorb C) was used as substrate. Further, Wallace and Wallace (1994) reported that when a polyacrylamide gel (Broadleaf P4) was placed $5 \mathrm{~cm}$ beneath the soil it supplied water to the plants during one cycle with its water absorption capacity being lost afterwards.

There is no doubt that synthetic soil conditioners have established their usefulness as improvers of the physical properties of sandy soils. However, information on their effectiveness over a period of time is lacking. Therefore, the present study evaluates the effectiveness of polyacrylamide (Broadleaf P4) on the physical properties of soil which is subjected to a number of wetting and drying cycles.

\section{Materials and Methods}

SOIL PREPARATION: Calcareous sandy soil (Typic Torripsammant) was collected from the College Experimental and Research Station at Deirab, $40 \mathrm{~km}$ south west of Riyadh, Saudi Arabia. The sample was air dried and passed through a 2-mm sieve. Soil properties are given in detail by Choudhary et al. (1995). The conditioner used is a cross-linked, Na- polyacrylamide. It is granular, insoluble, nonhazardous and commercially known as Broadleaf P4. It is also hydrophillic and absorbs water 400 times its weight. Appropriate amounts of the polymer were thoroughly hand mixed with $2 \mathrm{~kg}$ of air dried soil to obtain four concentrations of $0,0.2,0.4$ and $0.6 \%$ of the conditioner. Each treatment was replicated three times. Sub-samples were taken from each treatment, labeled as 0 cycle and stored.

WETTING AND DRYING CYCLES: For each treatment, $500 \mathrm{~g}$ of soil were placed in plastic containers of one liter capacity $(11 \times 11 \times 8 \mathrm{~cm})$. Based on the maximum water holding capacity (WHC) of each treatment, deionized water was added to bring the moisture content of the soil to $60 \%$ WHC. The weight of soil plus water was then recorded. The soil containers were placed inside a walk-in growth chamber with controlled light of $25.7 \mathrm{~W} \mathrm{~m}^{-2}$ and a constant temperature of $21 \pm 1^{\circ} \mathrm{C}$ for sixteen wetting and drying cycles. Water loss was determined on a weekly basis and distilled water was then added to bring the soil back to $60 \%$ WHC. At the end of 16 weeks, the soil samples were air dried, labeled as "16 cycles" and stored at room temperature. Soil samples from 0 and 16 cycles were then analyzed for the following physical properties.

WATER HOLDING CAPACITY: Water holding capacity (WHC) may be defined as the amount of water retained in soil at zero tension over and above the field capacity. It was determined by using $40 \mathrm{~mm}$ diameter plastic rings which were fitted with a stainless screen having openings $<2 \mathrm{~mm}$. Rings were filled with approximately $25 \mathrm{~g}$ soil and immersed half-way in deionized water for 24 hours to obtain maximum saturation. Excess water was drained by keeping the covered rings above glass funnels. After half an hour, soil and absorbed water was weighed and dried at $105^{\circ} \mathrm{C}$ overnight. The amount of water retained by the soil was calculated and termed WHC.

SOIL WATER RETENTION CURVES: Soil water curves were determined by the pressure plate apparatus (Richards, 1948). Soil was packed in brass rings $5 \mathrm{~cm}$ in diameter and $3 \mathrm{~cm}$ in height to a uniform bulk density $\left(1.5 \mathrm{~g} \mathrm{~cm}^{-3}\right)$ and saturated for $24 \mathrm{~h}$. The saturated samples were then subjected to matric potentials of $-10,-33,-66,-300$ and $-1500 \mathrm{kPa}$ and the retained moisture was calculated for the 0 and 16 cycles.

BULK DENSITY, POROSITY, VOID RATIO, COEFFICIENT OF LINEAR EXTENSIBILITY: Bulk density of the untreated and treated samples, both at the beginning of the experiment $(0$ cycle) and after 16 wetting and drying cycles, was determined by the core method 


\section{PHYSICAL PROPERTIES OF SANDY SOIL AFFECTED BY SOIL CONDITIONER UNDER WETTING AND DRYING CYCLES}

(Blake and Hartge, 1986). Porosity and void ratio were computed from the measured bulk density, assuming a particle density of sandy soil of $2.65 \mathrm{~g} \mathrm{~cm}^{-3}$.

The coefficient of linear extensibility (COLE) was determined by measuring the vertical free swelling of the treated and untreated soils (Sabrah, 1994) and is given as follows :

$$
\operatorname{COLE}=\left(\mathrm{V}_{\mathrm{m}} / \mathrm{V}_{\mathrm{d}}\right) /^{1 / 3}-1
$$

where

$\mathrm{V}_{\mathrm{m}}=$ volume of saturated soil sample in $\mathrm{cm}^{-3}$.

$\mathrm{V}_{\mathrm{d}}=$ volume of air-dried soil sample in $\mathrm{cm}^{-3}$.

AVAILABLE WATER: Available water content (AW) is the moisture retained in the soil between field capacity and permanent wilting point. It was calculated by the following equation :

$$
\mathrm{AW}=\theta_{\mathrm{FC}}-\theta_{\mathrm{pwp}}
$$

where

$$
\begin{aligned}
\theta_{\mathrm{FC}}= & \text { volumetric water content at field capacity } \\
& (-10 \mathrm{kPa}) \\
\theta_{\mathrm{pwp}}= & \text { volumetric water content at permanent } \\
& \text { wilting point }(-1500 \mathrm{kPa})
\end{aligned}
$$

SATURATED HYDRAULIC CONDUCTIVITY: The saturated hydraulic conductivity $\left(\mathbf{K}_{\mathrm{s}}\right)$ was determined with $2 \mathrm{~cm}$ constant head, using a cylindrical glass of $6 \mathrm{~cm}$ in diameter and $12 \mathrm{~cm}$ in height. The soil samples were placed in the cylinder to a $9 \mathrm{~cm}$ height at a uniform bulk density of $1.5 \mathrm{~g} \mathrm{~cm}^{-3}$. Saturated hydraulic conductivity was calculated suing Darcy's formula :

$$
\mathrm{K}_{\mathrm{s}}=(\mathrm{Q} / \mathrm{AT})(\mathrm{H} / \mathrm{L})
$$

where

$$
\begin{aligned}
\mathrm{K}_{\mathrm{s}}= & \text { saturated hydraulic conductivity }\left(\mathrm{cm} \mathrm{h}^{-1}\right) \\
\mathrm{Q}= & \text { volume of water }\left(\mathrm{cm}^{3}\right) \text { passed through } \\
& \text { the soil in time } \mathrm{T}(\mathrm{hr}) \\
\mathrm{L} \quad= & \text { length of soil column }(\mathrm{cm}) \\
\mathrm{H} \quad= & \text { total head }(\mathrm{cm}) \\
\mathrm{A} \quad= & \text { cross section area of the cylinder in } \mathrm{cm}^{2}
\end{aligned}
$$

Unsaturated hydraulic conductivity $K(\theta)$ was calculated according to the Campbell (1974) equation :

$$
K(\theta)=K_{s}\left(\theta / \theta_{s}\right)^{2 b+3}
$$

where

$K(\theta)=$ unsaturated hydraulic conductivity ( $\mathrm{cm}$ $\mathrm{h}^{-1}$ ) corresponding to volumetric content $(\theta)$

$\mathrm{K}_{\mathrm{s}} \quad=$ saturated hydraulic conductivity $\left(\mathrm{cm} \mathrm{h}^{-1}\right)$ $\theta_{s}=$ saturated soil water content

$\mathrm{b}=\mathrm{a}$ soil parameter which is calculated from the soil water retention curves as described by Cosby et al. (1984).

\section{Results and Discussion}

The water holding capacity (WHC) of the sandy soil treated with conditioner at $0.2,0.4$ and $0.6 \%$ increased significantly at 0 and 16 cycles (Figure 1). For the 0 wetting and drying cycle, the soil absorbed $64.3,182.8$ and $303.9 \%$ more water over untreated soil at $0.2,0.4$ and $0.6 \%$, respectively. After 16 wetting and drying cycles, the respective WHC values of these concentrations were $55.5,136.4$ and $243.2 \%$, i.e a reduction of $8.3,19.0$ and $20.0 \%$ compared to the 0 cycle. When differences between means of WHC for the 0 and 16 cycles were analyzed using $t$-test, results were significant at $\mathrm{P}<0.05$.

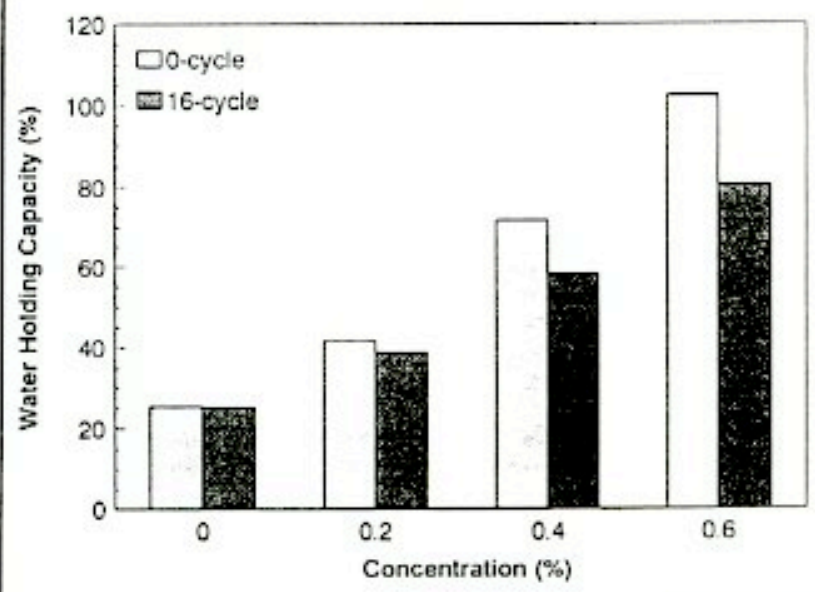

Figure 1. Water holding capacity (WHC) versus concentration of Broadleaf P4 for sandy soil at 0 and 16 cycles.

BULK DENSITY, POROSITY, VOID RATIO AND COEFFICIENT OF LINEAR EXTENSIBILITY: Bulk density decreased with increasing concentration of soil conditioner which reflected an increase in porosity and void ratio when compared to the untreated soil (Table 1). For the 0 wetting and drying cycle, the present decrease in bulk density in relation to the control was $44.3,58.2$ and $69.6 \%$ when soil was treated with conditioner at $0.2,0.4$ and $0.6 \%$, respectively. These values for the respective concentrations after 16 wetting and drying cycles were $39.9,50.0$, and $62.7 \%$.

The increase in porosity over the control was $67.5,87.5$, and $105.0 \%$ for the 0 wetting and drying cycles. The increase in void ratio over the untreated soil for the respective concentrations was 202.9, 347.7 and $580.6 \%$ at the 0 wetting and drying cycle and $162.7,247.8$, and $429.8 \%$ after 16 wetting and drying 


\section{TABLE 1}

Bulk density, porosity, void ratio, and COLE of sandy soil as affected by wetting and drying cycles during treatment with Broadleaf $P 4$

\begin{tabular}{ccccc}
\hline $\begin{array}{c}\text { Concentration } \\
\% \\
(\mathrm{w} / \mathrm{w})\end{array}$ & $\begin{array}{c}\text { Bulk } \\
\text { density } \\
\left(\mathrm{g} \mathrm{cm}^{-3}\right)\end{array}$ & Porosity & Void ratio & COLE \\
\hline \multicolumn{5}{c}{ 0 Cycle* } \\
\hline 0.0 & 1.58 & 0.40 & 0.67 & 0.00 \\
0.2 & 0.88 & 0.67 & 2.03 & 0.80 \\
0.4 & 0.66 & 0.75 & 3.00 & 1.40 \\
0.6 & 0.48 & 0.82 & 4.56 & 2.33 \\
$\mathrm{LSD}_{05}^{* *}$ & 0.06 & 0.04 & 0.60 & 0.09 \\
\hline & & 16 Cycle* & & \\
\hline 0.0 & 1.58 & 0.40 & 0.67 & 0.00 \\
0.2 & 0.95 & 0.64 & 1.76 & 0.66 \\
0.4 & 0.79 & 0.70 & 2.33 & 1.00 \\
0.6 & 0.59 & 0.78 & 3.55 & 1.67 \\
$L_{\text {LSD }}^{* *}$ & 0.06 & 0.02 & 0.29 & 0.09 \\
\hline
\end{tabular}

* Means of the two treatments ( 0 cycle and 16 cycle) were analyzed statistically using t-test and were found significant at $\mathrm{P}<0.05$ for the soil properties mentioned above.

** Least significant difference at five percent level.

cycles. Hoda (1994) reported that sandy soil treated with hydrogel conditioners exhibited an appreciable decrease in bulk density which is equivalent to an increase in porosity and void ratio as compared with the control. Similar results were also reported by Sabrah (1994). They attributed this appreciable decrease in bulk density to the formation and stabilization of soil aggregates. Furthermore, they reported that the swelling of such conditioners upon wetting tends to form numerous voids which decrease the bulk density and increase the porosity of treated soil. Overall, it appeared that appreciable changes had occurred in the soil properties with increasing concentration of the conditioner both at 0 and 16 wetting and drying cycles. For the 16 cycle the values for bulk density, porosity and void ratio were significantly different than for the 0 cycle. For example, differences in bulk density were $7.4,16.5$ and $18.5 \%$ for soil treated with $0.2,0.4$ and $0.6 \%$ conditioner, respectively. It is suggested that the beneficial effects of the Broadleaf $\mathrm{P} 4$ conditioner were more pronounced at the first wetting and drying cycle with its ability to affect the soil properties being decreased with further wetting and drying cycles.

It is obvious from the data in Table 1 that the swelling parameter, the coefficient of linear extensibility (COLE), increased with increasing concentrations of Broadleaf P4. Thus after 16 weeks of wetting and drying the effectiveness of soil conditioner was reduced and as a result the values of COLE decreased by $17.5,28.6$ and $27.4 \%$ at the three levels of use.

MOISTURE RETENTION AND AVAILABLE WATER: The effects of conditioner concentration on the relationship between soil matric suction $(\Psi)$ and volumetric soil water content $(\theta)$ in relation to wetting and drying cycles is shown in Figures 2 and 3. Addition of the conditioner resulted in a considerable increase in soil water retention both at 0 and 16 cycles. Generally, a sharp decrease in $\theta$ was observed with increasing $\Psi$ between -0.1 and $-10 \mathrm{kPa}$, which was followed by a gradual decrease in $\theta$ for larger values of $\Psi$. For example, at $\Psi=-33 \mathrm{kPa}$, addition of Broadleaf P4

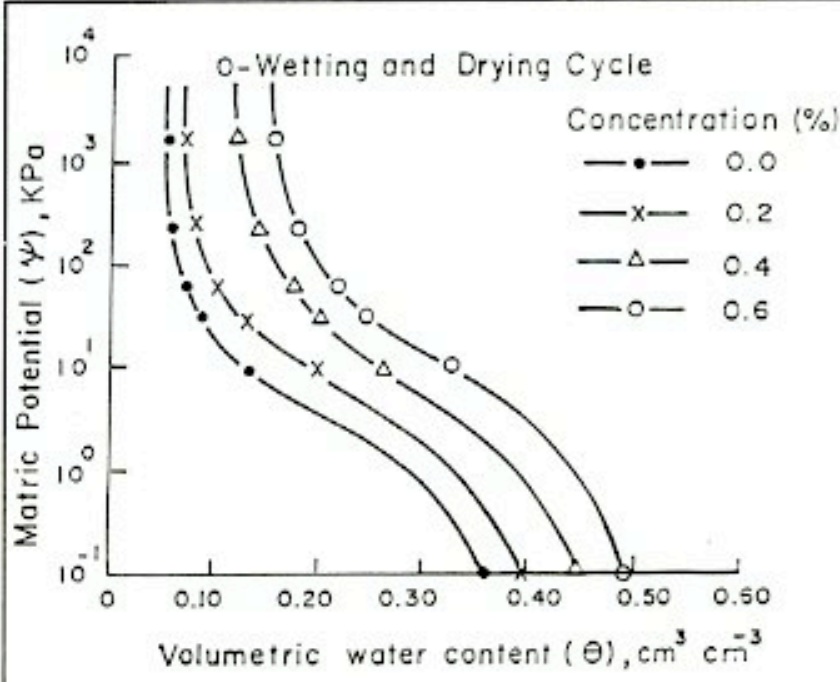

Figure 2. Relationship between matric potential $(\Psi)$ and water content $(\theta)$ of sandy soil treated with Broadleaf P4 at the 0 wetting and drying cycle.

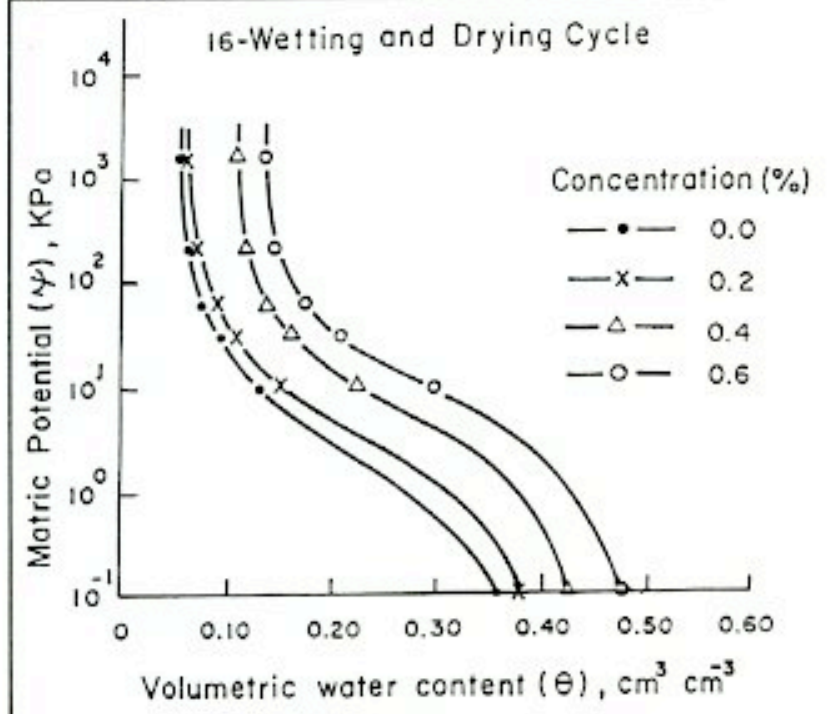

Figure 3. Relationship between matric potential $(\Psi)$ and water content $(\theta)$ of sandy soil treated with Broadleaf P4 after 16 wetting and drying cycles. 


\section{PHYSICAL PROPERTIES OF SANDY SOIL AFFECTED BY SOIL CONDITIONER UNDER WETTING AND DRYING CYCLES}

increased the water content of untreated soil from 0.09 to $0.13,0.20$ and $0.25 \mathrm{~cm}^{3} \mathrm{~cm}^{-3}$ when treated with 0.2 , 0.4 and $0.6 \%$ of the conditioner. These values were $0.11,0.17$ and $0.21 \mathrm{~cm}^{3} \mathrm{~cm}^{-3}$ after 16 cycles, i.e. a decrease of $16.9,16.0$ and $15.0 \%$ as compared to the respective concentrations at the 0 cycle.

Figure 4 shows the effect of wetting and drying cycles on the available water content of the sandy soil when treated with varying concentrations of Broadleaf $\mathrm{P} 4$. The increase in $\mathrm{AW}$ as a result of the addition of the conditioner was $85.7,102.9$ and $143.7 \%$ at the 0 cycle and $28.6,48.6$ and $128.6 \%$ at the 16 cycle. In conclusion, AW decreased significantly with increasing wetting and drying cycles in the treated soil. This effect was pronounced at $0.2 \%$, where a decrease of $30.2 \%$ in AW was observed whereas at the highest concentration $(0.6 \%)$ the decrease was only $6.2 \%$. This result suggests that the Broadleaf P4 should be applied at a rate higher than $0.2 \%$ to increase the $\mathrm{AW}$ of sandy soil. Similar results were observed by AlHarbi et al. (1996) where the relative water content and water-use efficiency in the cucumber plant increased significantly by raising the amount of Broadleaf P4 from 0.2 to $0.6 \%$.

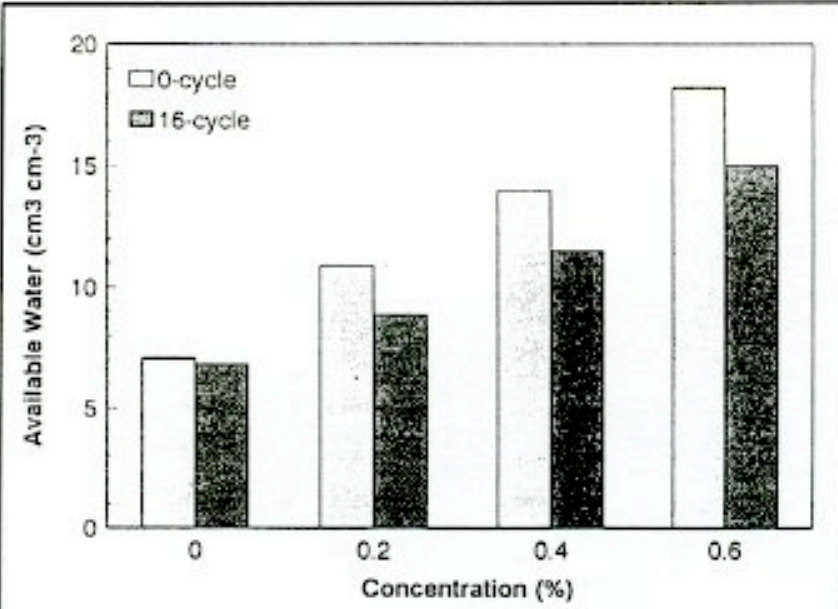

Figure 4. Available water (AW) versus Broadleaf P4 concentration for sandy soil at 0 and 16 cycles.

SATURATED AND UNSATURATED HYDRAULIC CONDUCTIVITY: Saturated hydraulic conductivity (Ks) decreased with increasing the concentration of soil conditioner in both treatments (Figure 5). For the 0 cycle, $K_{\mathrm{s}}$ was reduced by $44.0,68.7$ and $82.5 \%$ with increasing concentrations of Broadleaf P4. For the 16 cycle, $\mathrm{K}_{\mathrm{s}}$ values for the respective concentrations of conditioner were reduced by $14.8,27.4$ and $37.9 \%$. The decrease is attributed to the reduction in effective mean pore radius as a result of the soil expansion (Mustafa et al., 1988; Al-Darby, 1996). It was evident from the above data that Broadleaf P4 was effective in reducing $K_{s}$ at 0 cycle whereas after 16 wetting and

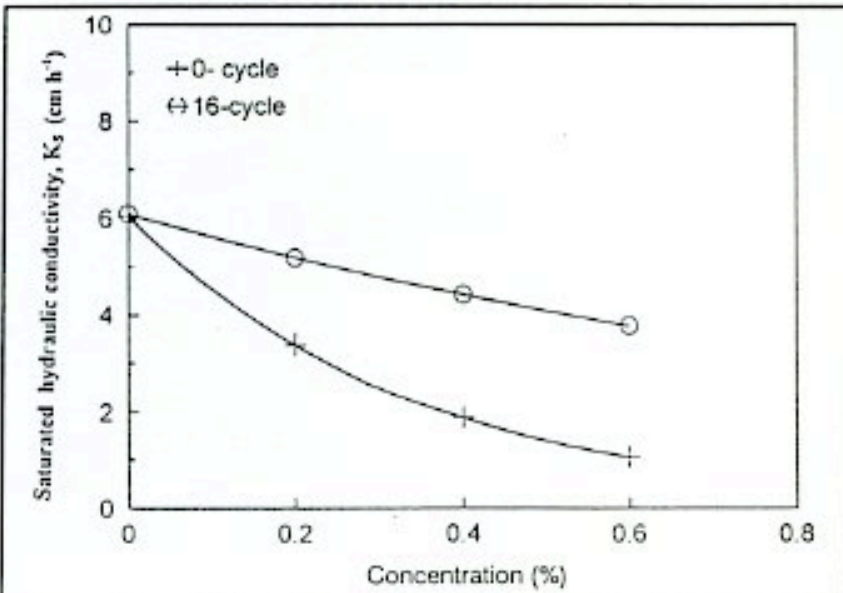

Figure 5. Hydraulic conductivity versus Broadleaf P4 concentration for sandy soil at 0 and 16 cycles.

drying cycles its ability to reduce $\mathrm{K}_{\mathrm{s}}$ was decreased by $34.9,54.3$ and $72.0 \%$ at the respective concentrations. When the values of $\mathrm{K}_{\mathrm{s}}$ were applied to the permeability classes of saturated soil (Kohnke, 1968), the addition of conditioner converted the permeability class of soil from moderately rapid and moderate to moderately slow when the conditioner was used at $0.2,0.4$ and $0.6 \%$. In the 16 cycle the permeability class changed from moderately rapid to moderate when the soil was treated at higher concentrations $(0.4$ and $0.6 \%)$.

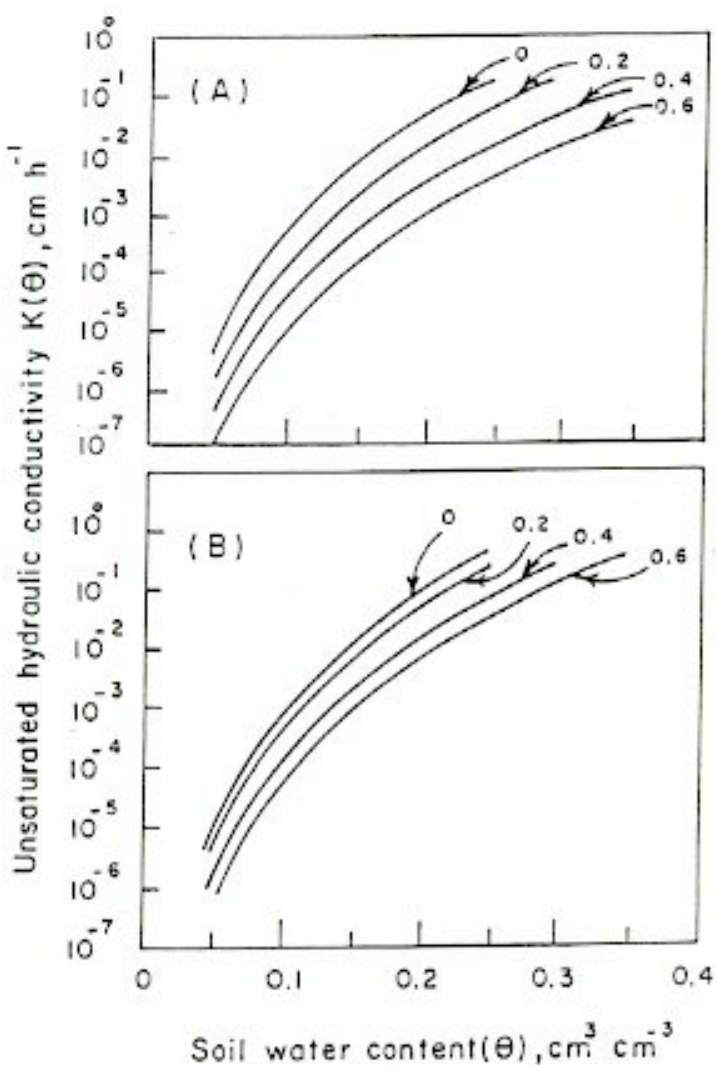

Figure 6. Relation between unsaturated hydraulic conductivity and moisture of sandy soil treated with four concentrations of Broadleaf P4 at (A) 0 cycle and (B) 16 cycle of wetting and drying. 
The unsaturated hydraulic conductivity $\mathrm{K}(\theta)$ of the soil also increased considerably with increasing moisture content $(\theta)$ and decreased with increasing concentrations of Broadleaf P4 (Figures $6 \mathrm{~A}$ and $\mathrm{B}$ ). This may be attributed to the water retention and swelling of the conditioner which resulted in a reduced mean pore radius of the soil.

\section{Conclusions}

Appreciable changes have occurred in the physical properties of sandy soil with increasing rates of polymer when it was subjected to wetting and drying cycles. The beneficial effects of Broadleaf P4 conditioner were more pronounced at the 0 wetting and drying cycle. Its ability to affect the physical conditions of sandy soil decreased with increasing wetting and drying cycles. This ability diminished greatly at $0.2 \%$, moderately at $0.4 \%$ and comparatively less at $0.6 \%$ conditioner. Changes in soil properties such as bulk density, porosity, void ratio and COLE were found to be significant $(\mathrm{P}<0.05)$. However, the data suggested that even after 16 weeks of wetting and drying cycles, the beneficial ability of Broadleaf P4 to change these properties persists, as compared to untreated soil. It is suggested that if this material is used in greenhouses for growing vegetables and ornamental plants, its beneficial effects would last up to three or four years. However, further research is recommended to test the effectiveness of such materials under field conditions.

\section{References}

Al-Darby, A.M. 1996. The hydraulic properties of sandy soil treated with gel-forming conditioner. Soil Techn. 9:15-28.

Al-Darby, A.M., Y.Z. El-Shafei, A.A. Shalaby and M. Mursi. 1992. Influence of a gel forming conditioner on water retention, infiltration capacity and water distribution in uniform and stratified sandy soils. Arid Soil Res. and Rehab. 6:145-161.

Al-Harbi, A.R., A.M. Al-Omran, M.I. Chaudhary, H. Wahdan, and M. Mursi. 1996. Influence of soil conditioner rate on seed germination and growth of cucumber plants (cucumis sativus L.) Arab Gulf J. Sci. Res. 14:129-142.

Al-Omran, A.M., A.M. Mustafa and A.A. Shalaby. 1987. Intermittent evaporation from soil columns as affected by a gel-forming conditioner. Soil Sci. Soc. Am. J. 51:1593-1599.

Azzam, R. O.A. Al-Hady, A.A. Lotfy and M. Hegela. 1983. Sand-RAPG combination simulating fertile clayey soils, Part I to IV. Int. Atomic Energy Agency. SM-267/15:321-349.

Blake, G.R. and K.H. Hartge. 1986. Bulk Density. P. 363-376. In. A. Klute (Ed.) Method of Soil Analysis, Part 1 2nd Ed. Agron. Mongr. 9: ASA and SSA, Madison, WI.

Campbell, G.S. 1974. A simple method for determining unsaturated conductivity from moisture retention data. Soil Sci. 117:311-314.

Choudhary, M.I., A.A. Shalaby and A.M. Al-Omran. 1995. Water holding capacity and evaporation of calcareous soil as affected by four synthetic polymers. Commun. Soil Sci. Plant Anal. 26:2205-2215.

Cosby, B.J., G.M. Hornberger, R.B. Clapp and T.R. Ginn. 1984. A statistical exploration of the relationships of soil moisture characteristic to the physical properties of soils. Water Resour. Res. 20:682-690.

De Boodt, M. 1975. Use of soil conditioners around the world. p 1-12. In: Soil Conditioners. SSA. Special Publication No. 7. Madison, WI, U.S.A.

Falatah, A.M. and A.M. Al-Omran. 1995. Impact of soil conditioner on some selected chemical properties of a calcareous soil. Arid Soil Res. Rehab. 9:91-96.

Falatah, A.M., M.I. Choudhary and A.M. Al-Omran. 1996. Changes in some chemical properties of arid soil as affected by synthetic polymers. Arid Soil. Res. Rehab. 10:277-285.

Fonteno, W.C. and T.E. Bilderback. 1993. Impact of hydrogel on physical properties of coarse-textured horticultural substrates. J. Am. Soc. Hort. Sci. 118:217-222.

Fox, D. and R.B. Bryan. 1992. Influence of a polyacrylamide soil conditioner on run off generation and soil erosion. Field tests in Baringo District, Kenya. Soil Techn. 5:101-119.

Hoda, M.S. 1994. Improvement of tomato production under the desert conditions. M.S. thesis. Institute of Environ. Studies and Res. Ain Shamas University, Egypt.

Kohnke, H. 1968. Soil physics. McGraw-Hill Book Company, New York. Pp. 224

Levy, G.J., J. Levin, M. Gal, M. Ben-Hur and I. Shainberg. 1992. Polymer's effects on infiltration and soil erosion during consecutive simulated sprinkler irrigations. Soil Sci. Soc. Am. J. 56:902-907.

Mustafa, M.A., A.M. Al-Omran, A.A. Shalaby and A.M. AlDarby. 1988. Horizontal infiltration of water in soil columns as affected by a gel-forming conditioner. Soil Sci. 145:330336.

Richard, L.A. 1948. Porous plate apparatus for measuring moisture retention and transmission by soil. Soil Sci. 60:105-110.

Sabrah, R.E.A. 1994. Water movement in a conditioner treated sandy soil in Saudi Arabia. J. Arid Environ. 27:363-373.

Seybold, C.A. 1994. Polyacrylamide review. Soil conditioning and environmental fate. Commun. Soil Sci. Plant Anal. 25:2171-2185.

Shainberg, I., D.N. Warrington and P. Rengasamy. 1990. Water quality and PAM interactions in reducing surface sealing. Soil Sci. 149:301-307.

Wallace, A. and G.A. Wallace. 1990. Soil and crop improvement with water-soluble polymers. Soil Techn. 3:1-8.

Wallace, A. and G.A. Wallace. 1994. Failure of gel polymers to save huge amounts of irrigation water. Commun. Soil Sci. Plant Anal. 25:117-118.

Wallace, A. and G.A. Wallace and A.M. Abouzamzam. 1986. Effects of excess of levels of a polymer as a soil conditioner on yields and mineral nutrition of plants. Soil Sci. 141:377380 .

Wang, Y.T. and L.L. Gregg. 1990. Hydrophilic polymers-their response to amendments and effect on properties of a soiless potting mix. J. Am. Soc. Hort. Sci. 115:943-948. 